\title{
DOCUMENTS
}

\author{
L. J. van Rossum
}

\section{EIN UNVERÖFFENTLICHTER BRIEF TROCKIJS VON ANFANG 1916}

Der nachstehend zum ersten Male veröffentlichte Brief Trockijs an die niederländische Sozialistin Henriette Roland Holst ist aus zwei Gründen interessant. Der Brief ermöglicht eine wichtige Korrektur der im Westen gängigen Vorstellung vom Verhältnis Trockijs zu Lenin im Jahre 1916. ${ }^{1}$ Zudem enthält er einige, die Entstehungsgeschichte des Blattes Vorbote ergänzende Fakten.

Jeder, der sich mit der Geschichte der russischen Revolution beschäftigt, stösst auf den Unterschied im Verhältnis Lenin-Trockij vor 1914 und nach 1917. Vor 1914 wesentlich divergierende Auffassungen zu theoretischen und praktisch-organisatorischen Fragen und eine gegenseitige Antipathie, die in scharf polemischen Ausfällen zum Ausdruck kommt; seit 1917 - schon bald nach der Februarrevolution analoge Anschauungen über die nach dem Fall des Zarismus anzuwendende revolutionäre Strategie und Taktik, schliesslich nach der Oktoberrevolution enge und konstruktive Zusammenarbeit in der Sowjetregierung, wobei Differenzen in staatspolitischen Fragen auf sachliche Weise angefasst werden. ${ }^{2}$

Um diese Veränderung zu erklären, weisen Deutscher und Brahm auf die Bedeutung der Kriegsfrage hin, die seit August 1914 alle Beziehungen innerhalb der russischen Sozialdemokratie beherrschte. Die Konsequenzen, die die Menschewiki aus dem Kriegsausbruch und dem Zusammenbruch der II. Internationale zogen, vergrösserten den

\footnotetext{
1 Diese Vorstellung ist vor allem geprägt durch I. Deutscher, The Prophet Armed, Trotzky: 1879-1921, London 1954; wichtig ist ausserdem Heinz Brahm, Trotzkijs Kampf um die Nachfolge Lenins, Die ideologische Auseinandersetzung 1923-1926, Köln 1964. Zum Standpunkt der sowjetischen Historiographie s. Anm. 2.

${ }^{2}$ Sowjetische Historiker bestreiten die Richtigkeit des hier skizzierten Bildes. In ihren Augen hat die Tatsache, dass Trockij der bolschewistischen Partei im August 1917 beitrat, nur formale Bedeutung, in Wirklichkeit führte er - versteckte und offene - Opposition gegen den Leninismus. Wo die Auffassungen Lenins und Trockijs über staatspolitische Fragen auseinandergingen, wird dies als Konsequenz des Trockij'schen Antibolschewismus ausgelegt. Vgl. die jüngste sowjetische Veröffentlichung über Trockij: Trockizm - Vrag Leninizma, Moskva 1968, S. 5.
} 
Abstand zwischen ihnen und Trockij ständig, ohne dass dieser jedoch den Standpunkt der Bolschewiki übernahm. Wohl anerkannte Trockij, dass die Bolschewiki den Sozialpatriotismus am konsequentesten bekämpften, mit Lenins These, die Niederlage des eigenen Landes sei das kleinere Übel, stimmte er jedoch nicht überein. Seiner Ansicht nach unterschätzten die Bolschewiki das revolutionäre Potential des Kampfes für den Frieden. Nach dem Ausbruch der Februarrevolution verloren diese Meinungsverschiedenheiten allerdings an Bedeutung, und mit der Entwicklung der Leninschen Auffassungen über die Möglichkeiten der russischen Revolution, die in dessen Aprilthesen zum Ausdruck kam, stand dem Zusammengehen kein grundsätzlicher Gegensatz mehr im Wege. ${ }^{1}$

Obwohl diese Darstellung in grossen Zügen richtig ist, liegt ihre Schwäche darin, dass sie Differenzen zwischen Lenin und Trockij in den Jahren 1914-17 in den Hintergrund treten lässt, Differenzen, denen die beiden Protagonisten selbst grosses Gewicht beimassen. Kommt Lenin in den Schriften jener Jahre auf Trockij zu sprechen, so ist sein Hauptvorwurf, Trockijs revolutionärer Internationalismus sei rein verbal und hindere ihn nicht, Verbindungen zu Gruppen zu halten, deren Auffassungen er nicht teile. Trockij handele genau wie die deutschen Zentristen, und Lenin spricht denn auch in diesem $\mathrm{Zu}$ sammenhang von Trockijs "Kautskyismus". So schrieb Lenin Ende Juli 1915 in einem Brief an den Tribunisten" Wijnkoop, in dem er zunächst Henriette Roland Holst ${ }^{3}$ kritisiert und als einen holländischen Kautsky definiert hatte: „Ganz wie unser Herr Trotzky: 'prinzipiell entschieden gegen die Landesverteidigung' - praktisch für die Einigkeit mit der Fraktion Tcheidze in russischer Duma (d.h. mit den Gegnern

1 Die hier nur angedeutete Entwicklung in den Auffassungen Lenins bzw. Trockijs sind ausführlich behandelt bei Deutscher, The Prophet Armed, besonders S. 223-227 und 233-238, und Brahm, Trotzkijs Kampf, S. 47-52.

${ }^{2}$ De Tribune erschien seit 1907 und vereinigte um sich die Linksopposition innerhalb der niederländischen Sociaal Democratische Arbeiderspartij (SDAP). Auf dem Parteikongress von 1909 stimmte die Mehrheit dafür, das Blatt einzustellen. Die Tribunisten verliessen die Partei und gründeten die Sociaal Democratische Partij (SDP), deren Zentralorgan De Tribune wurde.

${ }^{3}$ Nach der organisatorischen Spaltung der niederländischen Sozialdemokratie (s. Anm. 2) blieb H. Roland Holst, die bis 1909 an De Tribune mitgearbeitet hatte, zunächst bis 1912 Mitglied der SDAP. 1915 gründete sie eine eigene Organisation (Revolutionair Socialistisch Verbond - RSV), die die Zusammenarbeit von SDAP und SDP befürwortete. Im Januar 1916 gab das RSV diesen Standpunkt auf, vgl. dazu H. Roland Holst, „Der Kampf um Zimmerwald in Holland", in: Vorbote 1916, Nr 1, S. 64-68, wo die Notwendigkeit der organisatorischen Abspaltung der "Internationalen" von den "Sozialpatrioten und Sozialimperialisten" für die Arbeiterbewegung aller Länder unterstrichen wurde. Das RSV schloss sich zu dieser Zeit der Zimmerwalder Linken an. 
unserer nach Sibirien geschickten Fraktion, mit den besten Freunden russischer Sozialchauvinisten)."1

Umgekehrt warf Trockij Lenin und seiner Gruppe vor: „Unterordnung von Problemen der politischen Aktion unter solche der organisatorischen Abgrenzung; gleichermassen feindliche Haltung gegenüber denen, die die Grundprinzipien ihres Programms ablehnen, wie denen gegenüber, die sich nicht vor jeder Kleinigkeit ihrer sektiererischen Plattform verbeugen. Dass diese Gruppe besser organisiert ist, entspricht vollständig ihrer Tendenz, sich selbst abzuschliessen."2 Für Trockij war es diese "sektiererische" Haltung, die gemeinsamen Aktionen der russischen Internationalisten aus allen Fraktionen im Wege stand; nach der Februarrevolution ,entbolschewisierten" sich die Bolschewiki in dieser Hinsicht, ${ }^{3}$ und der Eintritt Trockijs und seiner Fraktion in die Partei wurde diesen möglich. Dass Trockij jedoch Anfang 1916 noch grösste Vorbehalte gegen ein Zusammengehen hatte, zeigt unser Brief deutlich. ${ }^{4}$

Zum besseren Verständnis der im Brief erörterten Fragen der Zusammensetzung und der Befugnisse der Redaktion des Vorbote folgendes.

Vorbote, Internationale Marxistische Rundschau, erschien mit zwei Nummern, vom Januar bzw. April 1916 datiert, in der Schweiz. Als Herausgeber zeichneten die Niederländer Anton Pannekoek und Henriette Roland Holst, die selbst je zwei Beiträge lieferten. Ferner enthielten die beiden Nummern Beiträge der Bolschewiki Lenin (2), G. E. Zinov'ev (3), S. M. Gopner (1), des Polen K. Radek (3), des Niederländers D. Wijnkoop (1), des Österreichers Franz Koritschoner (1); hinter dem bisher nicht aufgelösten Pseudonym Paul Bremer (1)

${ }^{1}$ Zitiert nach W. I. Lenin, Briefe, Bd IV, August 1914 - Oktober 1917, Berlin 1967, S. 101. Für entsprechende Äusserungen in Lenins Artikeln und Broschüren der Jahre 1914-1917 s. V.I. Lenin, Polnoe Sobranie Sočinenij, Moskva 19631965 , Bd 26, S. 295 ; Bd 27, S. 236 ; Bd 30, S. 234, 237, 270-271. Nach Lenins Meinung brach Trockij erst nach seiner Rückkehr aus Petrograd definitiv mit dieser halbherzigen Haltung, vgl. Lenin, a.a.O., Bd 34, S. 345.

2 [L.D.] Trockij, „Pod bremenem ob"ektivizma”, in: Naše Slovo, 24. November 1915. Analoge Åusserungen Trockijs in Naše Slovo vom 23. Juli 1915, 6. Oktober 1915 und 16. Mai 1916.

${ }^{3}$ Leninskij Sbornik, Bd IV, Moskva 1925, S. 303.

4 Deutscher meint zu Unrecht, Trockij habe seit 1916 die Annäherung an die Bolschewiki zum Prinzip der Redaktionspolitik von Naše Slovo gemacht (The Prophet Armed, S. 235). In Wirklichkeit setzte Trockij seine Versuche fort, die Internationalisten aller Fraktionen zu vereinigen. Anscheinend bleibt Deutscher an dieser Stelle unter dem Einfluss von Trockijs Selbstdarstellung: „Meinungsverschiedenheiten, die mich in Zimmerwald noch von Lenin getrennt hatten, wurden in den nächsten Monaten völlig ausgeglichen." (Leo Trotzki, Mein Leben, Berlin 1930, S. 240). 
verbirgt sich wahrscheinlich ein deutscher Mitarbeiter. Das Blatt fungierte als Organ der Zimmerwalder Linken. Im Leitartikel der ersten Nummer erklärten die Herausgeber, mit der Zimmerwalder Linken ,,auf dem gleichen Boden" zu stehen und Aufgabe des Blattes sei es, die praktisch-politische Arbeit dieser Gruppe durch die Publikation eines theoretischen Diskussionsorgans zu unterstützen. ${ }^{1}$ Diese Bestimmung der eigenen Position in "Zur Einführung” wurde dadurch unterstrichen, dass man anschliessend den Resolutionsentwurf abdruckte, den die Zimmerwalder Linke auf der Konferenz von Zimmerwald (5.-9. September 1915) eingebracht hatte. ${ }^{2}$

Die Verhandlungen über die Zusammensetzung der Redaktion des Vorbote waren langwierig und schwierig. Uns stehen hier nicht alle einschlägigen Quellen zur Verfügung, und die im folgenden versuchte Rekonstruktion dieser Vorgänge lässt darum einige Fragen offen. ${ }^{3}$ Schon im Frühjahr 1915 planten die Tribunisten H. Gorter und A. Pannekoek die Herausgabe eines internationalen theoretischen Organs, das Kautskys Neue Zeit bekämpfen sollte. Sie nahmen Kontakt mit Radek und Lenin auf, diese reagierten positiv, aber der Plan scheiterte an Geldmangel. Dies änderte sich, als sich Henriette Roland Holst etwa im September 1915 bereit erklärte, ein solches Blatt herauszugeben und zu finanzieren. Sie verband damit allerdings die $\mathrm{Be}-$ dingung, dass man auch ausserhalb des ihrer Meinung nach zu engen Kreises der Tribunisten und Leninisten Mitarbeiter gewinnen müsse, und bestand auf der Teilnahme von Trockij. ${ }^{4}$ Die ursprünglichen

1 Vorbote, Nr 1, S. 4.

${ }^{2}$ Ebd., S. 5-6. Zur Entstehungsgeschichte der Resolution vor und zu den Diskussionen darüber während der Konferenz vgl. Die Zimmerwalder Bewegung, Protokolle und Korrespondenz, hrsg. von Horst Lademacher, The Hague 1967 [1968], Bd 1, S. 116-149, und Ja. G. Temkin, Lenin i meždunarodnaja socialdemokratija, 1914-1917, Moskva 1968, S. 221-237.

3 Die Zimmerwalder Bewegung, Bd 2, Korrespondenz, enthält mit Ausnahme zweier Briefe von Roland Holst an Pannekoek vom März 1916 und des hier veröffentlichten Trockij-Briefes alle Briefe von Radek, Roland Holst, Pannekoek und Wijnkoop, die sich auf die Zusammensetzung der Redaktion des Vorbote beziehen und im Besitz des IISG sind. V.I. Lenin, Polnoe Sobranie Sočinenij, Bd 49, enthält Briefe von Lenin zu diesem Thema. Leninizm ob imperialističeskij vojne, Sbornik, Moskva 1932, T. 1 enthält ein Brieffragment von Trockij an M.S. Urickij. Die Weise, wie Temkin, Lenin i meždunarodnaja social-demokratija. auf Quellen im Central'nyj Partijnyj Archiv Instituta Marksizma-Leninizma in Moskau verweist, lässt vermuten, dass sich dort noch unveröffentlichte Dokumente Lenins zu Zimmerwalder Bewegung und Vorbote befinden, vgl. Temkin, a.a.O., S. 266 und 277.

4 Roland Holst hatte Trockij 1907 auf dem Internationalen Sozialistenkongress in Stuttgart kennengelernt. 1915 schrieb sie die Einleitung zur niederländischen Ausgabe von Trockijs Der Krieg und die Internationale (Leo N. Trotzky, De oorlog en de Internationale, vertaald door $\mathrm{H}$. Ide Bottenheim, met een inleiding 
Initiatoren gerieten durch dieses Angebot einigermassen in Verlegenheit, sie fanden die Standpunkte Roland Holsts wie auch Trockijs zu zentristisch. H. Gorter zog sich überhaupt zurück, Lenin und Radek waren dagegen unter der Bedingung einverstanden, dass Pannekoek als ihr Vertreter in die Redaktion aufgenommen und den festen Mitarbeitern (ausser Lenin, Radek und Trockij u.a. J. Borchardt und F. Mehring) das Recht zugestanden wurde, auch „strittige” Artikel in dem Blatt $\mathrm{zu}$ veröffentlichen. Trockij wurde daraufhin von zwei Seiten zur Mitarbeit eingeladen, ${ }^{1}$ stimmte grundsätzlich $\mathrm{zu}$ und verband damit folgende Vorstellung: „Um Roland Holst als meine Vertreterin gruppiert sich ein Stab im Grossen und Ganzen gleichgesinnter Mitarbeiter: die Gruppe Naše Slovo, Deutsche von Internationale, einige Franzosen, ${ }^{2}$ Rakovskij und andere. Deren gegenseitiges Verhältnis garantiert eine Koalitionszeitschrift, in der die Extremisten durch Pannekoek vertreten werden."3

Eine Ånderung des Organisationskonzept im Dezember schien allerdings für solche Pläne keinen Raum mehr zu lassen: das Büro der Zimmerwalder Linken (Lenin, Zinov'ev und Radek) erhielt gewisse redaktionelle Rechte, das Blatt sollte nun in der Schweiz erscheinen und Radek als Redaktionssekretär fungieren. Mit Radek, der sich „vom blassrosa Internationalismus zum Leninistischen Extremismus entwickelt hat", als Redaktionssekretär, wurde die Redaktion Roland Holst - Pannekoek zur Fiktion, die Lenins Wirklichkeit werden. ${ }^{4}$ Trockij bat denn auch Urickij, Roland Holst mitzuteilen, die Gruppe Naše Slovo könne nur dann mitarbeiten, wenn durch die Zusammensetzung der Redaktion der Koalitionscharakter der Zeitschrift gesichert sei. Ob Urickij dieser Bitte nachgekommen ist, lässt sich nicht feststellen, sicher ist, dass Trockij zwei bis drei Wochen später definitiv absagte. Ausserdem teilte er mit, er könne seinen französischen Freunden die Mitarbeit nicht empfehlen. ${ }^{5}$

van Henriette Roland Holst, Amsterdam 1915). Auf der Zimmerwalder Konferenz brachte sie zusammen mit Trockij einen Manifest-Entwurf ein, der die Mitte zwischen den Entwürfen der Zentristen und der Leninisten halten sollte, vgl. Die Zimmerwalder Bewegung, Bd 1, S. 134-137.

1 Briefe von Roland Holst von Oktober und Radek von November 1915. Roland Holsts Brief wurde wahrscheinlich durch die Pariser Polizei abgefangen, vgl. A. Kriegel, Le Dossier de Trotski à la Préfecture de police de Paris, in: Cahiers du monde russe et soviétique, 1963, S. 295, Anm. 1.

2 A. Merrheim, A. Rosmer, P. Monatte.

3 Trockij an Urickij, ca. Ende Dezember 1915, in Leninizm ob imperialističeskoj vojne, priloženija, S. 62; Trockij schrieb wegen schlechter Verbindungen nicht direkt an Roland Holst.

4 Ebenda, S. 62-63.

5 Brief von Lenin an I. F. Armand vom 21. Januar 1916, Lenin, Briefe, Bd IV, S. 172. Der Brief von Trockij, (an Radek gerichtet) liegt nicht vor. 
Für die Pläne der Redaktion war dies ein schwerer Schlag: man hatte die Franzosen A. Merrheim und A. Rosmer als Mitarbeiter gewinnen wollen, und Lenin hatte sogar eine französische Ausgabe des Blattes erwogen. ${ }^{1}$ Zur selben Zeit beschloss Henriette Roland Holst nach Rücksprache mit Pannekoek, die Zusammensetzung der Redaktion noch einmal zu ändern: die Zahl der Redakteure wurde auf zwei Anton Pannekoek und Henriette Roland Holst - reduziert, die drej Mitglieder des Büros der Zimmerwalder Linken zu Mitarbeitern degradiert. ${ }^{2}$ Über die Beweggründe für diesen Entschluss von Roland Holst geben die Quellen keinen Aufschluss. Dass Trockijs Absage den Beschluss beeinflusste, ist denkbar.

Der Brief, der maschinenschriftlich vorliegt, wird originalgetreu abgedruckt, lediglich die Rechtschreibung wurde modernisiert. Warum Trockij russisch schrieb, lässt sich nur vermuten: Einerseits ist bekannt, dass Trockij die deutsche Sprache hinreichend beherrschte, um sich mündlich wie schriftlich frei ausdrücken zu können, andererseits besass Henriette Roland Holst eine gute passive Kenntnis des Russischen. Möglicherweise plante Trockij anfänglich, seine Antwort als offenen Brief in Naše Slovo zu veröffentlichen.

Der Brief ist nicht datiert, aus seinem Inhalt ist jedoch zu schliessen, dass er nicht vor Februar 1916 geschrieben sein kann. Das Original befindet sich in der Kollektion Henriette Roland Holst, IISG, Amsterdam. Der Brief wurde von Hans Siegfried Lamm ins Deutsche übersetzt.

Дорогой друг,

я получил от Вас новое настоятельное приглашение сотрудничать в „Vorbote” и почти в тот же день получил No 1 этого журнала. И я не мог не поразиться той вопиющей разниџей, которая су-

1 Temkin, Lenin i meždunarodnaja social-demokratija, S. 260. Der Vorbote enthielt keinen einzigen Beitrag von französischer Seite; die in Vorbote, $\mathrm{Nr} 1$, S. 54-58 unter dem Pseudonym Nat. veröffentlichten „Eindrücke vom Parteitag der französischen Sozialdemokratie" stammten von der in Paris lebenden Bolschewikin S. M. Gopner. Ihr Parteiname war Nataša.

2 Als Lenin anlässlich der Reorganisation der Redaktion im Namen des Büros der Zimmerwalder Linken gewisse Garantien für die Mitarbeiter forderte, antwortete ihm Roland Holst, dass diese die gleichen Rechte wie die zwei Redakteure hätten und sich auch zu Fragen äussern könnten, in denen die Redakteure anderer Meinung seien (vgl. Temkin, Lenin i meždunarodnaja socialdemokratija, S. 263, wo sich eine Zusammenfassung der im Central'nyj Partijnyj Archiv aufbewahrten Antwort von Roland Holst findet). Aus den Quellen wird nicht deutlich, ob dieser Briefwechsel vor oder nach dem Satz der ersten Nummer stattfand. 
шествует между самим журналом и между характеристикой, которую Вы ему даете в Вашем письме. Вы пишете о коалијионном журнале, в котором должны сотрудничать все революџионноинтернаџионалистские элементы, при чем Вы называете группы: ленинскую, „Нашего Слова”, „Internazionale”, Раковского, левых Французов и пр. Между тем ,Vorbote” является органом так называемой џиммервальдской левой, т.е. группы Ленина. Проект ленинской резолюџии напечатан в виде основной платформы журнала и во вступительной статье заявлено о том, что журнал исходит именно из резолюџии џиммервальдской левой. В то же время в первой книжке в качестве сотрудников, кроме Вас лично, фигурируют только ленинџы. Что же это значит?

Прежде всего - о принџипиальной стороне дела. Журнал не может не поразить всякого критического читателя своей идейной бедностью. На циммервальдской конференџии мы с Вами могли голосовать за передачу в комиссию проекта ленинской резолюции, хотя я лично тогда заявил о том, что он дает в высшей степени недостаточное выражение некоторым крайне важным вопросам. Но там дело шло о политически боевом объединении, о действии. Здесь же дело идет о журнале, об органе критики и пропаганды. Если там во имя непосредственно политического эффекта можно было условно дать свою подпись под документом в духе самого примитивного вульгаризирования соџиалрадикализма, то является преступлением против теории, политики и ... литературного вкуса делать такого рода документ платформой журнала.

Раз известная группа решилась на 19-м месяџе войны выступить перед немецкой аудиторией со свонм словом, то эта претензия должна была бы быть оправдана серьезностью и внушительностью этого слова. Первая книжка должна бы быть составлена с тем большим сознанием теоретической и политической ответственности, что книжка выпускается не немџами на немеџком языке. Между тем, как я уже сказал, № 1 поразих меня бедностью своего теоретического содержания. То, что в нем сказано, было уже однажды напечатано в журнале ,Коммунист” девять месяџев тому назад. Вообџе, вместо коалиџионного органа, о котором Вы пишете, мы, русские, увидали перед собою перевод на немеџкий язык ленинского журнала, Коммунист”. Я не думаю, чтобы такой журнал мог сгруппировать вокруг себя серьезные силы в сфере немецкого и франџузского рабочего движения. Я слишком хорошо знаю, скакимпренебрежением здесь отнеслись к летучему листку џиммервальдской левой, чтобы не сомневаться в этом. Вы не должны в конџе конџов забывать, что у лениншев нет - и по моему, не может быть - единомышленников ни в Германии, ни во Франџии, ни в Англии. Русские и гол- 
ландские экстремисты вместе не могут создать интернаџионала. Голландский экстремизм есть продукт неподвижной мелкобуржуазной среды; русский экстремизм есть продукт аморфной и некультурной сошиальной среды, где первое историческое движение пролетариата естественно требует упрощения и вульгаризаџии теории и политики. Надеяться, что русские и голландские өкстремисты, издавая журнал на немешком языке, окажутся способными через голову левых элементов организовать рабочих, значит ударяться в чисто ленинские утопии. Поставить журнал можно было только, вступив в соглашение с известными группами Германии и Франџии, и, заранее закрепив за собою право на пропаганду революционно-соџиалистических тенденџий в журнале. Вы же пошли совсем иным путем: вы отдали журнал группе ленинџев, которая пользуется им со всей свойственной ей бесџеремонностью, а затем уговариваете остальных примкнуть к этому предприятию. Но всякий скажет Вам: на обложке журнала мы читаем, что соиздательницей его является Ролланд-Хольст, а к статье РолландХольст какая то таинственная редакуия делает примечание в том смысле, что скромная и робкая попытка Ролланд-Хольст отмежеваться от голландских экстремистов является как бы неуместной. При сем в примеqании неведомой редакции к статье соиздательниџы журнала сообџается о точке зрения русских ленинџев на вопрос о праве самоопределения. Я слишком хорошо знаю лениншев, чтобы удивляться этой развязности. Но неужели Вы думаете, что этот журнал может сгруппировать сейчас вокруг себя, в том виде, в каком он существует теперь, широкий круг лиџ? Что касается „Нашего Слова", то участие в журнале нашей группы явилось бы прямым курьезом. В статьях действительных, а не формальных редакторов журнала, т.е. Аенина, Зиновьева, Радека, о „Нашем Слове” говорится как о газете, которая враждебна ,нашей партии" (при чем под нашей партией Ленин понимает Р.С.Д.Р.П., которую он считает своей партией). Когда же действительные редакторы „Vorbote" џитируют из „Нашего Слова" критику франџузского соџиалистического конгресса и заимствуют статистические данные, характеризующие состав конгресса, они скромно опускают указание на источник своих цитат, дабы читатель ,,Vorbote” не узнал, что „Наше Слово” занимает революционно-социалистическую позиџию. Я слишком хорошо, повторяю, знаю әту публику, чтобы чему нибудь удивляться. Но только тем, что Вы слишком мало знаете ее, я объясняю повторное настояние Ваше на сотрудничестве нашей группы в ,,Vorbote”.

Что касается приглашения Каутского и других, то я лично такого предложения не вносия, и не думаю, чтобы при настояшем поло- 
жении вешей это было необходимо или достижимо. С другой стороны при наличности левой (не формально-экстремистской, а действительно революџионно-марксистской) редакџии сотрудничество Каутского или Фридриха Аллера, если бы оно оказалось осуществимым, не заключало бы в себе никаких опасностей, ибо означало бы капитуляџию немеџкого џентра перед левой, и появление статьи Каутского в журнале того типа, о котором я говорю, приобрело бы, разумеется огромное агитаџионное значение, толкнув многих к журналу, в котором хозяином оставалась бы крайняя левая. Но все говорит мне, что это чистейшая утопия. Положение у Каутского далеко не настолько определилось, чтобы он решился на такого рода ответственный шаг, а делать какие бы то ни было принџипиальные уступки его тенденџиям для того, чтобы заручиться его сотрудничеством, я был бы, разумеется, не согласен. Единственная уступка, которую следовало бы сделать - это держаться более приличного тона по отношению к Каутскому, который все же за последнее полугодие систематически передвигается влево. Но әта уступка в тоне не была бы уступкой Каутскому, а уступкой политическому такту и литературному вкусу. Но, повторяю, для меня вопрос о журнале совершенно не связан с приглашением Каутского и вообше левого немеџкого и австрийского пентра. Дело идет только об обеспечении журналу такой редакџии и такого ведения всего издания, при котором действительно была бы возможна колмективная работа левых и әкстремистских әлементов. Не забудьте, что нас не так много и что индивидуальный авторитет каждого из нас в интернаџионале не так велик, как авторитеты тех, против которых нам приходится вести жестокую борьбу. Дело, следовательно, идет для нас о противопоставлении индивидуальным авторитетам коллективных авторитетов, которые могут сложиться на почве коллективной теоретической и политической работы. Но ленининзм есть исключение всякой коллективности. Если Ленин не мог отказать себе в удовольствии сделать примечание к Вашей статье, то чего же ждать от него по отношению к тем сотрудникам, которые не являются в то же время издателями журнала. Вот почему я остаюсь џеликом при своем отказе от участия в журнале в том виде, как он есть, и мои ближайшие друзья франшузы со мною в этом совершенно согласны.

В заключение позвольте сказать Вам по поводу Вашей статьи (әто, разумеется, не имеет уже отношения к тому вопросу, которому посвяшено настояшее письмо), что Вы сделали, с моей точки зрения, очень большой шаг в сторону экстремизма. Ваша формалистическая постановка вопроса об организаџионном расколе кажется мне неправильной. Столь же, если еше не более, неправильным - в 
другой плоскости - кажется мне Ваше суждение о праве наџий на самоопределение. Вы говорите, что при капитализме это право неосушествимо, при соџиализме - излишне. Почему оно излишне при соџиализме, это мне непонятно. Но казалось бы, что наша политика теперь исходит из убеждения в том, что мы входим в эпоху соџиальной революџии. Стало быть нам нужно иметь программу для соџиальной революџии, программу пролетарского государственного режима в Европе. Неужели же излишним является сказать полякам, сербам, эльзасџам, какой режим обеспечит им европейский пролетариат, ставший у власти? Ужели Вы думаете, что наџиональные трения и вопросы исчезнут с лиџа земли, как только пролетариат станет у власти? Я думаю - наоборот: они тогда только и развернутся во всей своей глубине и остроте и потребуют полного ответа. И нам нужно дать ответ, какое содержание получит право на самоопределение в условиях пролетарского режима, а не просто отмахиваться от этого права, как от мелкобуржуазной илююзии.

Мои франџузские друзья выпускают первомайский номер журнала, для которого они хотели бы иметь статьи иностранных товаришей. Они просили меня обратиться в частности к Вам, что я сим и выполняю. Надеюсь, что Вы разрешите соответственную статью напечатать одновременно и в „Нашем Слове”. Мой отказ сотрудничать в ,Vorbote" нисколько, разумеется, не относится к Вам лично - в этом Вы не можете сомневаться - $и$ во всяком издании, где Вы являетесь действительнылм редактором, я буду сотрудничать с большой радостью. Надеюсь поэтому, что отказ нашей группы и мой сотрудничать в ленинском по сушеству журнале не изменит Ваших добрых чувств к „Нашему Слову”. Ни одной статьи от Вас мы до сих пор не получили, в том числе и тех, которые Вы послали через Берн. Достаточно ли энергично Вы написали Гримму, чтобы он послал их нам немедленно же по получении?

Крепко жму Вашу руку и желаю всего хорошего.

Ваш Троџкий.

\section{[Übersetzung]}

Liebe Freundin,

ich erhielt von Ihnen eine erneute dringende Einladung zur Mitarbeit an Vorbote und bekam fast am selben Tag die Nr 1 dieser Zeitschrift. Dabei musste ich mich doch sehr über den krassen Unterschied zwischen der Zeitschrift selbst und der Charakteristik wundern, die Sie in Threm Brief von der Zeitschrift geben. Sie schreiben von einer Koalitionszeitschrift, an der alle revolutionär -- internationalistischen 
Elemente mitarbeiten sollen, wobei Sie folgende Gruppen nennen: die Leninsche, [die Gruppe von] Naše Slovo, ${ }^{1}$ Internazionale, ${ }^{2}$ [die Gruppe] Rakovskijs, ${ }^{3}$ [die Gruppe] der linken Franzosen usf. Indessen ist Vorbote das Organ der sogenannten Zimmerwalder Linken, d.h. der Lenin-Gruppe. Der Entwurf der Leninschen Resolution ist als Grundplattform der Zeitschrift abgedruckt, und im einleitenden Artikel heisst es, dass die Zeitschrift gerade von der Resolution der Zimmerwalder Linken ausgehe. ${ }^{4}$ Indessen sind im ersten Heft als Mitarbeiter, mit Ausnahme von Ihnen selbst, nur Leninisten aufgeführt. Was aber bedeutet das?

Zunächst zur grundsätzlichen Seite der Sache: Die Zeitschrift muss jeden kritischen Leser durch ihre Gedankenarmut verblüffen. Auf der Zimmerwalder Konferenz konnte ich mit Ihnen dafür stimmen, dass der Entwurf der Leninschen Resolution an eine Kommission überwiesen werde, obwohl ich persönlich damals erklärte, dass er einige äusserst wichtige Fragen in höchst unzureichender Weise zum Ausdruck bringt. ${ }^{5}$ Dort ging es jedoch um einen politischen Kampfverband, um das Handeln. Hier aber geht es um eine Zeitschrift, um ein Organ der Kritik und der Propaganda. Konnte man dort um des unmittelbaren politischen Effektes willen mit einigem Vorbehalt ein im Geiste der primitivsten Vulgarisierung des Sozialradikalismus abgefasstes Do-

${ }^{1}$ Die Tageszeitung Naše Slovo erschien von Januar 1915 bis September 1916 in Paris. An ihr arbeiteten mit: Menschewiki-Internationalisten wie Ju. O. Martov; Fraktionslose wie L. D. Trockij und D. B. Rjazanov; bereits zu den Bolschewiki Tendierende wie V. A. Antonov-Ovseenko, schliesslich zeitweilige Ex-Leninisten wie A. V. Lunačarskij und D. Z. Manuil'skij. Bis August 1915 lag de facto die Chefredaktion bei Martov und Trockij gemeinsam, danach bei Trockij allein. An der Konferenz von Zimmerwald nahm Trockij als Delegierter von Naše Slovo teil.

2 Internazionale, gemeint sind natürlich die oppositionellen deutschen Sozialdemokraten um R. Luxemburg und K. Liebknecht, die "Gruppe Internationale". 3 Trockij meint die im Juli 1915 gegründete Interbalkanische Sozialistische Föderation. An ihr waren die sozialistischen Parteien Bulgariens (,Engherzige”), Griechenlands, Rumäniens und Serbiens beteiligt, Sekretär des Zentralbüros der Föderation war Ch. Rakovskij.

"Das ist formal falsch, die Resolution wird im Artikel „Zur Einführung" nicht genannt. Vgl. allerdings zur politischen Position der Redaktion von Vorbote unsere Einleitung, S. 254.

${ }^{5}$ Die Zimmerwalder Bewegung, Bd 1, Protokolle, registriert Trockijs Einwände nicht; den Protokollen lagen allerdings keine Stenogramme zugrunde. In Naše Slovo schrieb Trockij, der Entwurf formuliere die Friedensfrage oberflächlich und nicht prinzipiell genug, überdies bringe er in einer Art, die mit dem Problem selbst nichts zu tun habe, russische Angelegenheiten vor ein internationales Publikum. ([L.D.] T[rockij], „Naši Gruppirovki”, in: Naše Slovo, 6. Oktober 1915). Das Schicksal der Resolution ist bekannt: der Vorschlag, sie der Kommission zu überweisen, die auch das Manifest auszuarbeiten hatte, wurde mit 19 gegen 12 Stimmen abgelehnt. 
kument unterschreiben, so ist es ein Verbrechen gegen die Theorie, die Politik und ... den literarischen Geschmack, ein derartiges Dokument zur Plattform einer Zeitschrift zu machen.

Wenn sich eine bestimmte Gruppe schon entschloss, sich im 19. Monat des Krieges vor einem deutschen Publikum zu Wort zu melden, so hätte dieser Anspruch durch die Ernsthaftigkeit und Eindringlichkeit ihrer Aussage gerechtfertigt sein müssen. Das erste Heft hätte mit um so grösserem theoretischem und politischem Verantwortungsbewusstsein verfasst werden müssen, als es nicht von Deutschen in deutscher Sprache herausgegeben wird. Indessen versetzte mich, wie ich bereits sagte, die $\mathrm{Nr} 1$ durch die Dürftigkeit ihres theoretischen Inhalts in Erstaunen. Was darin gesagt ist, stand schon vor neun Monaten einmal in der Zeitschrift Kommunist. ${ }^{1}$ Überhaupt sehen wir Russen darin statt des Koalitionsorgans, von dem Sie schreiben, eine deutsche Übersetzung der Leninschen Zeitschrift Kommunist. Ich glaube nicht, dass solch eine Zeitschrift ernsthafte Kräfte in der deutschen und französischen Arbeiterbewegung um sich scharen kann. Ich weiss $\mathrm{zu}$ gut, welche Geringschätzung man hier gegenüber dem Flugblatt der Zimmerwalder Linken an den Tag gelegt hat, als dass ich daran nicht zweifeln müsste. ${ }^{2}$ Sie dürfen schliesslich nicht vergessen, dass die Leninisten weder in Deutschland noch in Frankreich noch in England Gleichgesinnte haben - und nach meiner Meinung auch nicht haben können. Die russischen und holländischen Extremisten können zusammen keine Internationale bilden. Der holländische Extremismus ist das Produkt eines starren kleinbürgerlichen Milieus; der russische Extremismus ist das Produkt eines amorphen, unkultivierten sozialen Milieus, in dem die erste historische Bewegung des Proletariats natürlicherweise eine Vereinfachung und Vulgarisierung der Theorie und der Politik erfordert. Darauf zu hoffen, dass die russischen und holländischen Extremisten sich als fähig erweisen würden, durch die Herausgabe einer deutschsprachigen Zeitschrift über die Köpfe der

1 Kommunist, Genf, September 1915, Nr 1-2. Herausgegeben von der Redaktion des zentralen Parteiorgans Social'-demokrat (Lenin und Zinov'ev), G. I. Pjatakov, E. E. Boš und N. I. Bucharin, wurde wegen Meinungsverschiedenheiten innerhalb der Redaktion nicht fortgesetzt. Kommunist enthielt zwölf Artikel, davon erschienen ein Artikel in vollständiger Übersetzung (A. Pannekoek, Der Imperialismus und die Aufgaben des Proletariats), ein anderer in gekürzter Form (Lenin, Der Opportunismus und der Zusammenbruch der II. Internationale) in Vorbote.

${ }^{2}$ Internationale Flugblätter, Nr 1, November 1915, vom Büro der Zimmerwalder Linken in Zürich herausgegeben. Hier wurden die von der „Linken” auf der Zimmerwalder Konferenz eingebrachten Entwürfe eines Manifests und einer Resolution mit einer kurzen Einleitung abgedruckt. Weitere Nummern sind nicht erschienen. 
linken Elemente hinweg die Arbeiter zu organisieren, heisst, in rein leninistische Utopien zu verfallen. Eine Zeitschrift hätte man nur dann herausgeben dürfen, wenn man mit bestimmten Gruppen Deutschlands und Frankreichs ein Übereinkommen getroffen und sich im voraus das Recht auf die Propagierung revolutionär-sozialistischer Tendenzen in der Zeitschrift gesichert hätte. Sie haben jedoch einen vollkommen anderen Weg beschritten: Sie haben die Zeitschrift der Gruppe der Leninisten gegeben, die mit der ihr eigenen Unverfrorenheit von ihr Gebrauch macht, und reden dann den übrigen zu, sich diesem Unternehmen anzuschliessen. Ein jeder wird Ihnen aber sagen: Auf dem Umschlag der Zeitschrift lesen wir, daß ihre Mitherausgeberin die Roland Holst ist, aber zu dem Artikel der Roland Holst macht irgendeine geheimnisvolle Redaktion eine Anmerkung in dem Sinne, dass der dürftige und bescheidene Versuch der Roland Holst, sich gegen die holländischen Extremisten abzugrenzen, gewissermassen unangebracht sei. ${ }^{1}$ Uberdies wird in der Anmerkung der geheimnisvollen Redaktion zu dem Aufsatz der Mitherausgeberin der Zeitschrift der Standpunkt der russischen Leninisten zur Frage des Rechts auf Selbstbestimmung mitgeteilt. Ich kenne die Leninisten zu gut, als dass ich mich über diese Dreistigkeit wundern würde. Aber glauben Sie denn etwa, dass diese Zeitschrift in der Art, wie sie jetzt existiert, im Augenblick einen breiten Personenkreis um sich scharen kann? Was Naše Slovo betrifft, so wäre die Mitwirkung unserer Gruppe an der Zeitschrift geradezu ein Kuriosum. In den Aufsätzen der tatsächlichen aber nicht formalen Redakteure der Zeitschrift, d.h. Lenins, Zinov'evs, Radeks, wird Naše Slovo als eine Zeitung dargestellt, die „unserer Partei” feindlich gesinnt sei (wobei Lenin unter „unsere Partei" die RSDAP versteht, die er für seine Partei hält). Wenn die wirklichen Redakteure des Vorbote jedoch aus Naše Slovo die Kritik am fran-

'Henriette Roland Holst, „Der Kampf um Zimmerwald in Holland”, in: Vorbote, Nr 1, S. 64-68. Die fragliche Anmerkung am Ende dieses Artikels lautet: „Die Darstellung der Differenzen zwischen den holländischen Marxisten in bezug auf die Zimmerwalder Konferenz - wie sie Gen. Holst gibt - scheint uns zum Teil schon überholt zu sein, da die Genossen aus der SDP wie aus dem Soz. Rev. Verband sich mit der Zimmerwalder Linken solidarisch erklärt haben. Was die Behandlung der Frage des Selbstbestimmungsrechtes anbetrifft, so stehen die russischen revolutionären Marxisten (das Zentralkomitee der russischen sozialdemokratischen Arbeiterpartei) auf dem Standpunkt, diese Losung müsse einen Bestandteil unserer antiimperialistischen Aktion und Agitation bilden. Wir werden in der nächsten Nummer unserer Rundschau Thesen veröffentlichen, die ihren Standpunkt darstellen. (Redaktion)." Der erste Satz dieser Anmerkung ist offensichtlich für Aussenstehende formuliert. In Wirklichkeit hielten die Tribunisten auch nach dem formellen Anschluss der SDP an die Zimmerwalder Linke Distanz zu dieser. Lenin war sich dessen deutlich bewusst. Vgl. Temkin, Lenin i meždunarodnaja social-demokratija, S. 270. 
zösischen sozialistischen Kongress zitieren und statistische Angaben übernehmen, die die Zusammensetzung des Kongresses charakterisieren, unterlassen sie bescheiden den Hinweis auf die Quelle ihrer Zitate, damit der Leser des Vorbote nicht erfährt, dass $N a$ še Slovo eine revolutionär-sozialistische Position einnimmt. ${ }^{1}$ Ich wiederhole: Ich kenne dieses Publikum zu gut, um mich über irgendetwas zu wundern. Nur damit aber, dass Sie es zu wenig kennen, erkläre ich es mir, dass Sie immer wieder auf die Mitarbeit unserer Gruppe an Vorbote drängen.

Was die Einladung an Kautsky und andere betrifft, so habe ich persönlich einen solchen Vorschlag nicht gemacht, und ich glaube nicht, dass dies bei der augenblicklichen Lage der Dinge notwendig oder erreichbar ist. Andererseits würde eine Mitarbeit Kautskys oder Friedrich Adlers, wenn sie sich als durchführbar erwiese, beim Bestehen einer linken (nicht formal extremistischen, sondern wirklich revolutionär-marxistischen) Redaktion keinerlei Gefahren in sich bergen, denn sie würde die Kapitulation des deutschen Zentrums vor der Linken bedeuten, und das Erscheinen eines Artikels von Kautsky in einer Zeitschrift des Typs, von dem ich spreche, gewänne natürlich eine ungeheure agitatorische Bedeutung, da es viele einer Zeitschrift zutriebe, in der die äusserste Linke weiterhin die Herrin bliebe. Mir scheint jedoch alles darauf hinzudeuten, dass das die reinste Utopie ist. Bei Kautsky haben sich die Dinge bei weitem noch nicht so geklärt, dass er sich zu einem derartigen verantwortungsvollen Schritt entschliessen würde, und ich wäre natürlich nicht damit einverstanden, wie immer geartete grundsätzliche Zugeständnisse an seine Tendenzen $\mathrm{zu}$ machen, nur um mich seiner Mitarbeit zu versichern. Das einzige Zugeständnis, das man machen müsste, wäre, sich eines geziemenderen Tones gegenüber Kautsky $z u$ befleissigen, der sich immerhin im letzten halben Jahr systematisch nach links bewegt. Dieses Zugeständnis im Umgangston wäre jedoch kein Zugeständnis an Kautsky, sondern ein Zugeständnis an den politischen Takt und den literarischen Geschmack. Aber - ich wiederhole es - für mich hängt die Frage der Zeitschrift ganz und gar nicht mit der Einladung an Kautsky und überhaupt an das linke deutsche und österreichische Zentrum zusammen. Es geht nur darum, dass der Zeitschrift eine solche Redaktion und eine solche Leitung der gesamten Herausgabe gesichert wird, dass wirklich eine kollektive Arbeit der linken und der extremistischen

1 Trockij irrt sich; der genannte Artikel von S. M. Gopner, „Eindrücke vom Parteitag der französischen Sozialdemokratie", enthält ausser einigen Ziffern, die mit denen des Berichts in Naše Slovo (A. Losovskij, „Kongres Francuzskoj Socialističeskoj Partii”, in: Naše Slovo, 5. und 6. Januar 1916) identisch sind, auch solche, die in diesem Bericht nicht vorkommen. Das Umgekehrte ist nicht festzustellen. 
Elemente ermöglicht würde. Vergessen Sie nicht, dass wir nicht so viele sind und dass die individuelle Autorität eines jeden von uns in der Internationale nicht so gross ist wie die Autorität jener, gegen die wir einen erbitterten Kampf führen müssen. Folglich geht es für uns darum, den individuellen Autoritäten kollektive Autoritäten gegenüberzustellen, die sich auf der Grundlage kollektiver theoretischer und politischer Arbeit herausbilden können. Der Leninismus bedeutet jedoch den Ausschluss jeglicher Kollektivität. Konnte Lenin sich schon nicht die Freude versagen, Anmerkungen zu Ihrem Artikel zu machen, was soll man dann erst von seinem Verhalten gegenüber jenen Mitarbeitern erwarten, die nicht zugleich Herausgeber der Zeitschrift sind? Das ist der Grund, warum ich voll und ganz bei meiner Weigerung bleibe, an der Zeitschrift, so wie sie ist, mitzuarbeiten, und meine nächsten Freunde, die Franzosen, sind mit mir darin vollkommen einverstanden.

Gestatten Sie mir zum Schluss, Ihnen zu Ihrem Artikel zu sagen (das hat natülich nichts mehr mit der Frage zu tun, der dieser Brief gewidmet ist), dass Sie, von meinem Standpunkt aus, einen sehr grossen Schritt zum Extremismus hin getan haben. Ihre formalistische Stellung der Frage der organisatorischen Spaltung scheint mir falsch. ${ }^{1}$ Ebenso falsch, wenn nicht noch falscher - auf einer anderen Ebene erscheint mir Ihre Ansicht über das Recht der Nationen auf Selbstbestimmung. Sie sagen, dass dieses Recht im Kapitalismus nicht verwirklichbar, im Sozialismus [jedoch] überflüssig sei. Warum es im Sozialismus überflüssig sein soll, ist mir unverständlich. Man sollte aber meinen, dass unsere Politik jetzt von der Überzeugung ausgeht, dass wir in eine Epoche der sozialen Revolution eintreten. Folglich müssen wir ein Programm für die soziale Revolution haben, das Programm eines proletarischen staatlichen Regimes in Europa. Ist es etwa überflüssig, den Polen, Serben, Elsässern zu sagen, welches Regime ihnen ein zur Macht gelangtes europäisches Proletariat sichern wird? Glauben Sie wirklich, dass die nationalen Reibereien und Probleme vom Erdboden verschwinden werden, sobald das Proletariat an die Macht gekommen ist? Ich denke, das Gegenteil ist der Fall: Sie werden erst dann in ihrer ganzen Tiefe und Schärfe akut werden und vollständige Beantwortung erfordern. Auch wir müssen die Frage beantworten, welchen Inhalt das Recht auf Selbstbestimmung unter den Bedingungen eines proletarischen Regimes bekommen wird, und dürfen dieses Recht nicht einfach als kleinbürgerliche Illusion abtun.

Meine französischen Freunde bringen eine 1.-Mai-Nummer der Zeitschrift heraus, für die sie gern Artikel von ausländischen Genossen

1 Vgl. S. 252, Anm. 3. 
hätten. Sie haben mich gebeten, mich insbesondere an Sie zu wenden, was ich hiermit tue. Ich hoffe, Sie gestatten, dass ein entsprechender Artikel gleichzeitig auch in Naše Slovo abgedruckt wird. ${ }^{1}$ Meine Weigerung, an Vorbote mitzuarbeiten, betrifft natürlich in keiner Weise Sie persönlich - daran dürfen Sie nicht zweifeln - und ich werde mit grosser Freude bei jeder Ausgabe mitarbeiten, bei der Sie wirklicher Redakteur sind. Ich hoffe deshalb, dass die Weigerung unserer Gruppe und meine eigene, an einer im Grunde leninistischen Zeitschrift mitzuarbeiten, nichts an Ihren guten Gefühlen gegenüber Naše Slovo ändern wird. Bislang haben wir noch keinen einzigen Artikel von Ihnen bekommen, so auch keinen von denen, die Sie über Bern geschickt haben. Haben Sie Grimm energisch genug geschrieben, dass er sie uns unverzüglich nach Erhalt schicken soll? 2

Ich drücke Ihnen fest die Hand und wünsche alles Gute.

Ihr Trockij

1 Es handelt sich um die von Merrheim und Rosmer geplante und herausgebrachte 1. Mai-Nummer der Union des Métaux. Weder diese noch die 1. MaiNummer von Naše Slovo enthalten einen Beitrag von Roland Holst.

${ }^{2}$ In einem Brief an R. Grimm vom 2. Februar 1916 klagte Roland Holst über ihre schlechten Verbindungen zu Trockij. „Direkt mit Trotzky verkehren kann ich unmöglich, es kommt nichts durch, nicht einmal Zeitschriften; ich habe Verbindungen via Norwegen, aber das dauert wochenlang." (Die Zimmerwalder Bewegung, Bd 2, S. 436.) Mit diesem Brief schickte sie eine Reihe von Artikeln über die niederländische Arbeiterbewegung und bat Grimm darum, sie weiterzuleiten. Der erste Teil davon erschien am 8. April 1916 mit einer Anmerkung, der Artikel habe die Redaktion mit grosser Verzögerung erreicht: Henriette Roland Holst, „Položenie i perspektivy gollandskogo rabočego dviženija, I, III, IV", in: Naše Slovo, 8., 21. und 22. April 1916. Der zweite Teil hat Paris nicht erreicht. 